\title{
Editorial to volume 100 of Biological Cybernetics
}

\author{
J. Leo van Hemmen
}

(C) Springer-Verlag 2009

The first issue of Biological Cybernetics appeared half a century ago. No editorial, no preface, it just appeared. What motivated the people who initiated the Journal and what remains of this vision for the Journal as it stands now and evolves into its future? Is it fair to project half a century of computational neuroscience expressed in the pages of this Journal into the future? Let us try.

There being no Editorial to volume 1 of Biological Cybernetics, what evidence do we have of its goals? The title gives us a lead. Cybernetics arose in the late forties as a movement that would have strong impact on science. The Journal appeared slightly more than a decade after the epoch-making book Cybernetics (Wiley, New York, 1948) of Norbert Wiener, who from its beginnings belonged to the Editorial Board (see Fig. 1 below) of Kybernetik, the original, German, name of the Journal. We now quote from Wiener's introduction to cybernetics in Scientific American (179/5:14-18) of the very same year, 1948:

"Cybernetics" is a word invented to define a new field in science. It combines under one heading the study of what in human context is sometimes loosely described as thinking and in engineering as control and communication. In other words, cybernetics attempts to find the common elements in the functioning of automatic machines and of the human nervous system, and to develop a theory which will cover the entire field of control and communication in machines and living organisms."

What part of the above description is insightful and what part should be relegated to history as fanciful rumination? First, what seems quite correct about the above statement is

J. L. van Hemmen $(\varangle)$

Physik Department T35, Technische Universität München,

85748 Garching bei München, Germany

e-mail: 1vh@tum.de its mechanistic point of view. It is only recently that people have begun to build electronic and mechanical devices to reconstitute sensory or motor functions for 'parts' of the body (as those of a machine) that were lost as a consequence of disease, injury, or abnormal development. Control and feedback, notions so explicitly stressed by Wiener, are essential to proper movement or perceptual discrimination. Formulated in a more pronounced way, feedback is neuroanatomically more prominent than feedforward connections but we have hardly begun to analyze and mathematically model feedback as a dominant element of neuronal functioning. It is a safe bet that analysis of neuronal feedback will blossom in the future.

To do all this, one needed and needs a far deeper understanding of neuronal functioning of the nervous system, far deeper than was available at Wiener's time. Here we face what seems wrong, even surprisingly wrong: Despite the suggestive "steersman", who like a homunculus "thinks", control and communication are not synonymous with thinking, whatever the latter may mean. Thinking is far more than just communication and control. It is a tantalizing task of computational neuroscience to find mathematical universals describing the bedazzling biological diversity and in this way unify the phenomenological multitude of the biological reality of a "thinking" brain.

With hindsight we can say it took neurobiology half a century to arrive at the point where we can construct neuroprosthetic devices to restore brain function. Synaptic learning is another essential ingredient of nervous functioning and, despite its emphasis upon control and feedback, the cybernetical focus was on stationary activity patterns. The 'perceptron convergence theorem' (see M. Minsky and

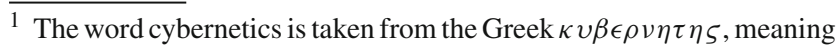
steersman.
} 
S. Papert, Perceptrons: An introduction to computational geometry, MIT Press, 1969) then initiated a bitter end to the cybernetic upsurge of learning by showing why most of what it wanted to achieve simply could not work.

In fact, neuronal activity patterns are nearly always spatiotemporal. In the late eighties there was a return to learning mechanisms that included time and turned out to be extremely fruitful, ending up in spike-timing-dependent plasticity or what is now simply called STDP, first predicted by theory and later verified experimentally. Computational neuroscience came into being as a field in its own right. That is, cybernetics turned 'biological', though our Journal had changed its name much earlier, a timely foreshadowing of what was to come. Since its conception, continuity has been one of the Journal's (many) virtues. My predecessor, Gert Hauske, was only the second Editor-in-Chief (1993-2005).

Following Werner Reichardt, the coinventor of the "Hassenstein-Reichardt" velocity detector and the founding Editor-in-Chief of the Journal, we intend to focus the Journal on publishing high-quality papers mainly in the field of computational neuroscience. As formulated in a previous Editorial (Biol Cybern 94:1, 2006), what my Coeditors-inChief, John Rinzel and Walter Senn, and I deem essential is an intertwining of a mathematically explicit theory and experimentation so as to describe and, more importantly, to understand the functioning of neurobiological systems. The time for "mathematizing" biology (for our purposes, read neurobiology) has come, and we should take advantage of it.

There is extensive evidence provided by the history of science that mathematization not only means applying mathematics but, far more importantly, first finding the right universal notions that allow applying mathematics successfully. A simple example that nearly everybody knows is Newton's second law $(\mathbf{F}=\mathrm{d} \mathbf{p} / \mathrm{d} t$ where the force $\mathbf{F}$ is on the left and the momentum $\mathbf{p}$ is on the right). Realizing that a particle's momentum $(\mathbf{p}=m \mathbf{v})$ is the key notion needed deep insight as it is by no means evident. Newton's law itself, however, is universal in the sense that, as a mathematical description, it applies to any mass and any force in classical mechanics, how different the situation each time may look from the previous one you have encountered. Finding universal biological notions that allow a consistent mathematical description of natural phenomena is a key challenge to computational neuroscience, an exciting perspective for some time to come. And it is safe to say that 'universal notions' do exist; for example, the neuron as a threshold element, the learning window of STDP, and the population-vector code.

Over the years the meaning of "computational" in the expression 'computational neuroscience', viz., a key element of what this Journal is devoted to, has changed. Quite frequently it is now taken to mean that the results of computational activity, in whatever branch of science, originate from large-scale numerical simulations. Though often quite valuable, they alone do not provide any explanation but only a description through numerical simulation of mathematical equations that are too complicated to be evaluated and understood by analytical means. That is, the underlying equations reproduce experiments through extensive numerical computations but do not explain them.

In accordance with the dominant role of mathematics in any quantitative formulation of processes in nature, be it biological, chemical, or physical, an alternative and more comprehensive name for many parts of computational neuroscience would be theoretical neuroscience, the adjective 'theoretical' simply expressing that mathematics is the essential ingredient in complementing, viz., quantifying, experimental neuroscience. There is no other means of quantitatively describing nature. In this way both computational and theoretical neuroscience are going to be comfortably embedded within Biological Cybernetics for next half century.

\section{J. Leo van Hemmen}

Editor-in-Chief 


\section{KYBERNETIK}

Zeitscbrift für Nacbricbtenübertragung, Nacbricbtenverarbeitung, Steuerung und Regelung in Organismen und in Automaten

A Journal Dealing with the Transmission and Processing of Information as well as with Control Processes in Both Organisms and Automata

HERAUSGEGEBEN VON · EDITED BY

H. B. BARLOW, CAMBRIDGE/ENGLAND · G. v. BÉKÉSY, CAMBRIDGE/MASS.

M.HALLE, CAMBRIDGE/MASS. - B. HASSENSTEIN, FREIBURG i. Br.

W.D. KEIDEL, ERLANGEN · I. KOHLER, INNSBRUCK · K. KUPFMULLER, DARMSTADT

H. MITTELSTAEDT, SEEWIESEN/OBB. · W. REICHARDT, TUBINGEN

W. A. ROSENBLITH, CAMBRIDGE/MASS. · J. F. SCHOUTEN, EINDHOVEN

M. SCHUTZENBERGER, POITIERS · K. STEINBUCH, KARLSRUHE

N. WIENER, CAMBRIDGE/MASS.

\section{BAND I}

$1961 / 1963$



SPRINGER -VERLAG • BERLIN • GOTTINGEN • HEIDELBERG

Fig. 1 Title page of Volume 1 of Biological Cybernetics as it originated in 1961 as 'Kybernetik'. The list of members of the Editorial Board started with Horace Barlow, with whom one will find an interview directly following this Editorial, and ended with Norbert Wiener. Many of the Editors such as von Békésy are still well-known and we can appreciate today that they were all first-class. For example, Karl Steinbuch (1917-2005) was a truly creative learning specialist, who published pioneering essays such as 'The learning matrix' in the first issue (pp. 36-45, 1961), developing a notion everybody now appreciates as self-evident 